\title{
Contribution of Telephone Conferences to Continuing Medical Education for Consultant Psychiatrists
}

\author{
C. P. SEAGER, Professor of Psychiatry, University of Sheffield
}

It is increasingly recognised that neither general medical nor specialist qualification marks the cessation of the need for continuing reinforcement and renewal of the well-known tripod of education, namely knowledge, skills and attitudes. It can be argued that experience is the great teacher and the day-to-day work of the graduate ensures a continuing updating. This is only partially correct since new knowledge and practices, together with changes in working relationships, may pass by the educationally isolated, leaving a person hidebound, prejudiced and reactionary on an island surrounded by a speeding torrent of change. Unthinking response to these pressures may not be the way to deal with the situation but an awareness of these changes, so that the choice of response is made from strength rather than weakness, is an essential aspect.

Brook \& Wakeford ${ }^{1}$ have demonstrated the limits of continuing medical education experienced by consultant psychiatrists. The situation in Britain is entirely voluntary but in many countries, particularly the United States and Australia, there are increasing pressures for compulsory re-training and re-certification at relatively short intervals.

With the closure of large mental hospitals and the dispersion of psychiatric services to District General Hospitals and Community Mental Health Centres, the numbers of psychiatrists working together become ever smaller. This may be no major problem in large conurbations, particularly those based on a university department which runs regular educational activities. Where psychiatric centres are scattered over relatively widespread areas based on small towns, the number of psychiatrists available may be measured in twos and threes rather than tens and twenties. Furthermore, because of the small numbers, it is an added difficulty for individuals to leave the area to attend postgraduate meetings, in addition to demands to cover for absences due to holidays and ill-health.

It may be unreasonable to expect senior experienced specialists in particular aspects of psychiatric practice to travel long distances from their home base to lecture to a relatively small audience, consisting of two or three consultants, one or two non-consultant medical staff and a handful of nurses and social workers. Distance learning must be considered as an alternative to the personal appearance. It has to be recognised that, at best, this is second best; it does not compare with the opportunities of face to face discussion and questioning which are available when the speaker is there in person. It has to be considered in the context of a substitute for the personal appearance. There are a number of options varying from the reading of books and journals to the use of audiotapes and videotapes, either absorbed individually or in groups, with a discussion led by a local tutor.

This paper describes a further option which offers another and possibly a more helpful compromise, since it does involve an opportunity for questions and answers and some interaction between the speakers themselves, as well as with their audiences. I would like to describe a series of telephone conferences carried out in Trent Regional Health Authority on four evenings during March 1987. This was the second experiment of this kind, the first having previously been reported. ${ }^{2}$

\section{Description}

British Telecom offers a Conference Service linking individuals together, or individuals with larger groups, the latter using a loudspeaker telephone system. Trent Regional Health Authority funded an experiment to link two speakers with five hospitals in which groups of consultants and other psychiatrists gathered together on each of four evenings in March 1987. The five centres were at Sheffield, Rotherham, Derby, Sleaford and Leicester. Each of these was equipped with a loudspeaker telephone which would enable an audience of up to about 20 to listen to a speaker and also respond, provided the questioner came close to the central microphone; unfortunately, it is not possible, for technical reasons, to have a roving microphone. These five hospitals each acted as centres for participants from psychiatric hospitals and units in the vicinity.

The speakers, two on each evening, gave their lectures either from their own homes or from the office at their own hospital. They had previously sent their slides or tables which were copied and distributed to each of the five recipient hospitals. I acted as co-ordinator and chairman on each of the five evenings. Each of the speakers was able to listen in to the other speaker and also to join in any discussions.

A number of other interested listeners came to one or more of the sessions. These included one of the regional postgraduate deans, a postgraduate tutor in a general hospital, two drug firm representatives and a professor of general practice. At the end of each session refreshments were provided at the hospitals; speakers in their own homes had to rely on their personal hospitality.

\section{Results}

Each hospital was supplied with feedback forms for each participant. Since each form covered the four evenings, 
those who attended less than four of the available sessions did not always complete their reply form or leave it with the local clinical tutor. It thus proved difficult to assess the total number of attendances and the response of the participants. Conclusions can therefore be only tentative, based on local discussions and comments made on the feedback forms.

Approximately 150 consultants were circulated and about 50 psychiatrists heard at least one of the evening sessions.

The assessment of the lectures was looked at from two different points of view; educational and technical. As far as the educational aspects were concerned, most listeners felt that this was an interesting experiment which did provide an opportunity for relatively isolated groups of doctors to hear experts in various fields.

Because Trent Regional Health Authority has three medical schools, it was probably a mistake to attempt to place three of the listening groups in postgraduate centres linked with the teaching hospitals. The attendance at these was least successful numerically and, indeed, one unit cancelled for technical reasons.

Information from the various listeners suggested that, from a professional or educational point of view, the idea was a good one and well worth pursuing. There was some complaint that the content of one or two of the talks was not of sufficiently specialist a level and provided too broad an approach. Others, however, felt that an overview of a particular subject was a valuable way of presenting this type of material.

There were a number of technical difficulties in connection with the lectures; we were fortunate in having the help of the senior British Telecom engineer associated with Conference Services so that we could benefit from his advice and he could appreciate the problems so that they could be rectified in the future. One serious difficulty was the clarity and volume of some of the speakers. This was partly related to their presentation, in that someone looking at notes or diagrams may drop the telephone microphone from in front of the mouth, leading to a fall-off in volume. At the receiving end, the type of room in which the loudspeaker is housed is also important, since the acoustic quality of large rooms is less satisfactory than small ones. Minor difficulties arose in contacting the different stations, since there were seven involved on each evening. The British Telecom Conference Operator was helpful in dealing with these technical problems.

There were minor difficulties in the distribution of slides, since it took some time to have slides copied and distributed to each of the centres. Speakers were asked to provide a photograph but this did not materialise in every case. A previous session had demonstrated that a photograph of the speaker was helpful for the recipients.

\section{Finances}

The costs were of two kinds: overt and covert. In the former were the charges by British Telecom for the loan of loudspeaker telephones at each of the five centres for a period of four weeks and the cost of the telephone calls on each of the four evenings from 7.30 to 9.15 p.m. In addition, there were fees to speakers and a payment to staff for copying the slides, as well as the cost of postage for distributing the slides.

Amongst the covert costs was the absorption of much of the cost of the slides into hospital budgets and also some of the telephone calls. One also has to take into account the travel costs for individual doctors getting to the Postgraduate Centre in the evening, after normal working hours. The total bill presented to Trent Regional Health Authority was of the order of $£ 1,300.00$ which covered the cost of eight postgraduate lectures by speakers from places as far apart as Edinburgh, London and Cardiff.

\section{Discussion}

In general, this experiment was well received by all the listeners, although there were a number of objections concerning the type of content, the quality of sound and the lack of personal interaction with the speaker. The speakers themselves found it uncomfortable to be talking into a microphone without any immediate response from their audience. There was an obvious feeling or relief at the end of the talk to hear some comments and questions and to realise that people had in fact been listening to what had been said. An alternative way of handling this situation would be for a videotape of the talk, with any illustrative material, to be sent to the Centre for playing to an audience who could then ring the speaker (by arrangement) to discuss the topic and ask any questions. The initial outlay, both of preparation and of equipment, would be high but the additional immediacy of questions to the speaker would add a dimension not usually available in a straightforward videotape presentation.

There is no doubt that all types of postgraduate teaching require considerable time and energy for preparation to achieve a useful lecture and to provoke adequate discussion. As a group, doctors tend to assume that teaching is not of great importance and can be done as a side issue during a few free moments between seeing patients. There are a few gifted speakers who, without notes, or perhaps with a few scribbles on the back of an envelope, can give a survey of their work in a sparkling, exciting and enthusiastic manner; these are people to be envied. The majority have to spend a lot of time on searching out their material, presenting it in the form of clear diagrams and tables and rehearsing it to give an impression of impromptu and casual presentation. The former few are to be envied by the latter majority.

The technical issues also require modification. The loudspeaker telephones were hired but could be purchased for approximately four times the hiring cost. Thus, if the system is to be used regularly, it would be an asset to possess one's own equipment. The speakers also would benefit from special equipment rather than a normal hand-held personal telephone. Either a telephone operator's headset with the microphone at a fixed distance in front of the mouth or a table microphone which would pick up the voice from two or three feet away would be more helpful. 
Conclusion

There have now been two Telephone Conferences in the Trent Region and evidence suggests that they are a possible alternative to visiting speakers or central educational meetings, both of which provide problems for psychiatrists working in relatively small, isolated units which seem likely to provide the pattern for future work. In order to fulfil their purpose as providers of Continuing Medical Education, it is important that a programme of lectures should be worked out, covering a range of topics fulfilling the needs of the psychiatrists who require updating in various aspects of their specialty. The Royal College of Psychiatrists is concerned with the training of future psychiatrists but has not neglected the need for CME. The Telephone Conference may be an additional means of fulfilling that role.

\section{ACKNOWLEDGEMENT}

I am indebted to Messrs Merck who offered hospitality at each of the hospital centres.

\section{REFERENCES}

'BROOK, P. \& WAKEPORD, R. (1987) Continuing medical education: a survey of consultant psychiatrists' attitudes and practices. Bulletin of the Royal College of Psychiatrists, 11, 38-42.

${ }^{2}$ Senger, C. P. (1985) The use of the telephone in continuing psychiatric education: sucoesses and failures. Bulletin of the Royal College of Psychiatrists, 9, 200-201.

\section{A Comment on 'Bridges over Troubled Waters: Services for Disturbed Adolescents'}

(A review by Peter Horrocks in Health Trends (1987), 19, 15-17)

John Evans, Young People's Unit, Royal Edinburgh Hospital, Edinburgh

The Hospital Advisory Service (HAS) was created in 1969 as a result of anxiety and embarrassment about the quality of long-term care for the elderly, the mentally ill and the mentally handicapped in England and Wales. The Scottish equivalent followed later. Since its inauguration, groups of multi-disciplinary specialists have visited hospitals, assessed practice, discussed shortcoming, offered advice and published reports. In recent months the HAS has received a brisk debate in the Bulletin of the College. Its function, and indeed the need for its existence, has been questioned. It is against that background that Peter Horrocks, Director of the NHS Health Advisory Service, has chosen to review existing psychiatric services for adolescents in England and Wales.

In the course of routine work it had become increasingly clear to the HAS that services for adolescents were being provided in an inconsistent, piecemeal fashion in the majority of Health Districts. "Difficult" young people perceived as disturbing by others and young people who are disturbed within themselves were causing quite disproportionate acrimony between professions and between organisations. The treatment and care they received seemed less related to real need than to the willingness of one or other organisation to accept responsibility. It was decided to investigate and to make recommendations. The conclusions were based on a visit to three English NHS Regions, 10 other Health Districts, one District in Wales and one in Scotland. In all, 50 individuals took part in the visits. Over a period of 18 months a number of multidisciplinary teams looked at existing services and the result is a 96 page Report making 107 specific recommendations. The main message was that adolescents frequently fall uncomfortably between provisions made for children and adults respectively.
Two issues emerged repeatedly. One was the need for the various agencies to stop 'buck-passing' and instead to collaborate to provide a co-ordinated service for young people. The other was the desperate need for more training and education about adolescents, not only for those specialising in the field, but also for those who meet adolescents only in the course of more general work.

The HAS discovered that very high quality services existed but these were out-numbered by others which were unduly selective, allowing misplacement of some young people and turning away others as "not our responsibility".

There was general agreement among the investigators that, while psychiatrists needed to take direct responsibility for the management of only a small proportion of disturbed adolescents, a greater psychiatric contribution to the assessment procedures of other agencies was badly needed.

The report makes a plea for a broad range of treatment options. How sensible. It is implicit, of course, that there be competence in the whole range of treatments provided but it is not spelled out how that can be achieved. It is a serious deficit in the training of adolescent psychiatrists.

It is $\mathbf{4 0}$ years since the first psychiatric services devoted entirely to adolescents came into being. Twenty-three years have elapsed since the Government Circular HM 64/4 first drew attention to the shortage of services for disturbed adolescents and their recommendation that there be 25 beds per million population. The response of Hospital Boards to the document in the next few years was so minimal that by 1967 they were formally requested to submit plans or explain why they did not have any and what they were doing about it.

The beneficial impact was that in the two decades that followed the number of units increased so that by 1981 there were 63 in existence that dealt, if only in part, with 